\title{
Sanctification or Inhibition? Religious Dualities and Sexual Satisfaction
}

\author{
Nathan D. Leonhardt \\ University of Toronto Mississauga \\ Dean M. Busby \\ Brigham Young University, dean_busby@byu.edu \\ Veronica R. Hanna-Walker \\ Brigham Young University \\ Chelom E. Leavitt \\ Brigham Young University
}

Follow this and additional works at: https://scholarsarchive.byu.edu/facpub

Part of the Other Social and Behavioral Sciences Commons

\section{Original Publication Citation}

Leonhardt, N. D., Busby, D. M., Hanna-Walker, V., \& Leavitt, C. E. (2020) Sanctification or inhibition? Religious dualities and sexual satisfaction. Journal of Family Psychology.

\section{BYU ScholarsArchive Citation}

Leonhardt, Nathan D.; Busby, Dean M.; Hanna-Walker, Veronica R.; and Leavitt, Chelom E., "Sanctification or Inhibition? Religious Dualities and Sexual Satisfaction" (2020). Faculty Publications. 4649.

https://scholarsarchive.byu.edu/facpub/4649

This Peer-Reviewed Article is brought to you for free and open access by BYU ScholarsArchive. It has been accepted for inclusion in Faculty Publications by an authorized administrator of BYU ScholarsArchive. For more information, please contact ellen_amatangelo@byu.edu. 


\section{Journal of Family Psychology}

\section{Sanctification or Inhibition? Religious Dualities and Sexual Satisfaction}

Nathan D. Leonhardt, Dean M. Busby, Veronica R. Hanna-Walker, and Chelom E. Leavitt

Online First Publication, September 3, 2020. http://dx.doi.org/10.1037/fam0000796

\section{CITATION}

Leonhardt, N. D., Busby, D. M., Hanna-Walker, V. R., \& Leavitt, C. E. (2020, September 3). Sanctification or Inhibition? Religious Dualities and Sexual Satisfaction. Journal of Family Psychology. Advance online publication. http://dx.doi.org/10.1037/fam0000796 


\title{
Sanctification or Inhibition? Religious Dualities and Sexual Satisfaction
}

\author{
Nathan D. Leonhardt \\ University of Toronto Mississauga
}

\author{
Dean M. Busby, Veronica R. Hanna-Walker, \\ and Chelom E. Leavitt \\ Brigham Young University
}

\begin{abstract}
Religiosity can influence sexual satisfaction both positively and negatively. To test positive and negative mechanisms, we assessed how religiosity is indirectly associated with sexual satisfaction through sexual sanctification and inhibited sexual passion. We sampled individuals from Amazon's Mechanical Turk $(N=1,695$, Study 1$)$ and mixed-sex dyads from Bovitz Inc. $(N=481$ dyads, Study 2$)$. Religiosity consistently had a positive indirect association with sexual satisfaction through sexual sanctification; little evidence suggested religiosity had an indirect association with sexual satisfaction through inhibited sexual passion. When accounting for these mechanisms simultaneously, however, religiosity consistently had a negative direct association with sexual satisfaction, supporting the possibility of religious dualities. In the couple study, men's religiosity predicted their partner reporting higher sexual sanctification (for married couples), but women's religiosity did not predict partner sexual sanctification. Altogether, these results paint a complex picture for how religiosity might influence sexuality. Understanding the nuance of these results may help people maximize the potential benefits of their belief systems in sexual relationships.
\end{abstract}

Keywords: religiosity, relationships, sexual passion, sexual sanctification, sexual satisfaction

Supplemental materials: http://dx.doi.org/10.1037/fam0000796.supp

Researchers have highlighted religion's potential to influence relationships in our family life (Dollahite, Marks, \& Dalton, 2018; Mahoney, 2010; Mahoney, Pargament, Tarakeshwar, \& Swank, 2001), but we have limited understanding of how this plays out in sexual relationships. Considering statements over the years concerning how religiosity informs the way we navigate sexuality (see Hernandez, Mahoney, \& Pargament, 2014 for a review), it would be beneficial to take a deeper look at the circumstances under which religiosity may help or hurt sexual well-being. The time is ripe for such an approach, as contraries seem abundant: scholars have found no association (Ashdown, Hackathorn, \& Clark, 2011), a positive association (Murray-Swank, Pargament, \& Mahoney, 2005; Hardy \& Willoughby, 2017), and a negative association (Davidson, Moore, \& Ullstrup, 2004) between religiosity and sexual satisfaction. One potential reason for the divergent results seen regarding religiosity is that scholars have often focused on religiosity as a global, distal phenomenon. Yet a variety of more proximal mechanisms might explain how religiosity's influence diverges (Mahoney et al., 1999).

D Nathan D. Leonhardt, Department of Psychology, University of Toronto Mississauga; (D) Dean M. Busby, Veronica R. Hanna-Walker, and (D) Chelom E. Leavitt, School of Family Life, Brigham Young University.

Preliminary findings for this article were presented at International Association for Relationship Research (IARR) in 2019. Complete findings were presented at International Academy of Sex Research (IASR) in 2020.

Correspondence concerning this article should be addressed to Nathan D. Leonhardt, Department of Psychology, University of Toronto Mississauga, 3359 Mississauga Road North, Toronto, ON L5L1C6, Canada. E-mail: nathan.leonhardt@mail.utoronto.ca
One recent study called for a dualistic perspective in assessing more proximal connections between religiosity and sexuality (Leonhardt, Busby, \& Willoughby, 2020). Highlighting the aforementioned tangle of associations, they suggested religiosity may indirectly influence sexual satisfaction through both positive and negative mechanisms. They suggested that religiosity could instill sexual sanctification (i.e. believing sexuality to have divine character and significance; Hernandez, Mahoney, \& Pargament, 2011), an attitude that can positively influence sexual satisfaction; they also suggested that religiosity could instill sexual guilt (i.e. a negative affective component, comprised of self-imposed punishment for either violating or expecting to violate "proper" sexual conduct; Hackathorn, Ashdown, \& Rife, 2016), an attitude that can negatively influence sexual satisfaction. Leonhardt et al. (2020) found that religiosity predicted higher sexual sanctification, which in turn predicted higher sexual satisfaction for both women and men; they did not find an indirect association with sexual satisfaction through sexual guilt. They did, however, find a direct negative association between religiosity and sexual satisfaction for women, after accounting for all variables simultaneously. This suggests alternative mechanisms may be playing a role in religiosity's potential to negatively influence sexual satisfaction.

In our study, we sought to replicate and expand on previous research showing that religiosity is positively associated with sexual satisfaction through sexual sanctification. We also sought to understand its potentially negative role by assessing inhibited sexual passion (i.e. feeling reluctant to act on sexual interest; Busby, Chiu, Leonhardt, \& Iliff, 2019) as a mechanism of negative influence. We explored associations of religiosity's role in sexual satisfaction for those in long-term committed 
relationships in a sample of individuals and a sample of mixedsex couples.

\section{Sexual Sanctification}

Sexuality has been cited in religious circles as the potential to be cocreators with God and also a way to enhance pleasure and bonding within a committed relationship (Hernandez et al., 2014); sexual sanctification is a construct used to try and capture this spiritual understanding of sexuality. Explaining sanctification is challenging, as sacred experiences are sometimes considered outside the realms of rational articulation. In previous research, scholars have conceptualized sexual sanctification as when individuals ascribe spiritual significance to sexuality, setting sex apart as something special and consecrating it to God. We focused on the more nontheistic component of sexual sanctification and conceptualized it as sex having holy or sacred attributes (Hernandez et al., 2011; Murray-Swank et al., 2005), as the construct is slightly more likely to be endorsed than the theistic component of sanctification (Hernandez et al., 2011), it may broaden application.

Psychological research cannot definitively determine the extent that sacred experience is reality or perception (Pargament, Oman, Pomerleau, \& Mahoney, 2017). Regardless, reporting sexuality to be sacred can influence the way someone thinks about and treats sexuality in their relationship. One study showed that sexual sanctification predicts higher sexual satisfaction, marital satisfaction, spiritual intimacy, and sexual intimacy (Hernandez et al., 2011); another study showed it longitudinally predicts higher sexual satisfaction, marital satisfaction, and more frequent sexual intercourse in newly married individuals (Hernandez-Kane \& Mahoney, 2018). Sexual sanctification has also been shown to predict increased sexual behavior and higher levels of sexual satisfaction in unmarried college students (Murray-Swank et al., 2005) and same-sex couples (Phillips et al., 2017). Research has also shown that religiosity indirectly predicts higher sexual satisfaction through sexual sanctification for long-term committed married and unmarried individuals (Leonhardt et al., 2020). This indirect prediction, however, was only found in one cross-sectional sample. It would be beneficial to replicate this finding. Furthermore, we do not know how these associations are manifest with dyadic data.

\section{Inhibited Sexual Passion}

Alternatively, some historical religious teachings have espoused sexuality as a natural depravity of the human body, a barrier to be overcome, and connected to original sin (Augustine, 400/1998; Schnarch, 1991). If someone integrated these attitudes into their relationship, that person would likely have sexual inhibitions (e.g., Buss, 2002; Freud, 1927/1961). Inhibited sexual passion is a recently developed construct that may tap into these negative attitudes. Inhibited sexual passion is not to be confused with sexual desire; inhibited sexual passion is more about how someone struggles to express their sexual interest. Perhaps the easiest comparison comes from the way some scholars conceptualize shyness. Shy individuals may desire to socially engage with peers, but social fears of rejection, or handling an interaction poorly, keep them from acting on their desire to engage (Coplan, Prakash, O'Neil, \& Armer, 2004). With inhibited sexual passion, the sexual interests are overcontrolled by internal (e.g., anxiety surrounding sex) or outside influences (e.g., being raised to think of sex as improper) that may potentially reinforce each other (Busby, Chiu, et al., 2019).

The vast majority of individuals have sexual interest (Bogaert, 2004). There are, however, a number of socio/cultural factors such as religiosity that may inhibit people from acting on that interest (e.g., Augustine, 400/1998; Buss, 2002). Several studies have suggested that religiosity is connected to an overall uneasiness surrounding sexuality (e.g., Emmers-Sommer, Allen, Schoenbauer, \& Burrell, 2018) possibly due to some religious teachings condemning sexual activity for pleasure rather than procreation (Cowden \& Bradshaw, 2007). For example, scholars have observed that more religious individuals are less likely to have multiple sexual partners (Davidson et al., 2004), less likely to believe that individuals should be able to engage in carefree, casual sex (Murray, Ciarrocchi, \& Murray-Swank, 2007), more likely to have negative attitudes toward nonprocreative sexual behavior (Davidson et al., 2004), and more likely to experience feelings of sexual guilt (with a recent meta-analysis revealing a robust correlation of $r=.44$; Emmers-Sommer et al., 2018). Much remains to be learned about religiosity's association with the recently created construct of inhibited sexual passion. But if some aforementioned negative attitudes of sexuality are instilled from religiosity, logically someone could hesitate to act on their sexual interest toward a partner.

Some may suggest that inhibited sexual passion is only associated with religiosity for unmarried couples. Hackathorn and colleagues (2016) found that sexual guilt mediated the relationship between religiosity and sexual satisfaction for unmarried individuals but not for those that were married. They called this finding the sacred bed phenomena, indicating that a possible reason for their results is that religious individuals consider sexual behaviors before marriage inappropriate and sinful (Rosenbaum \& Weathersbee, 2013), but these same behaviors are considered sacred after marriage, and therefore unlikely to instill negative feelings. On the other hand, some researchers have suggested that negative feelings about sexuality pervade even religious individuals who are married (Peterson, 1964), bringing a more permanent tension surrounding sexuality (Runkel, 1998), possibly due to some religious teachings condemning any sexual activity not dedicated to procreation (Cowden \& Bradshaw, 2007). Complicating the picture, one study of 1,614 participants in long-term relationships found that religiosity did not predict a single item index of sexual guilt for either married or unmarried individuals (Leonhardt et al., 2020). The extent to which religiosity is consistently associated with negative sexual attitudes (e.g., inhibited sexual passion) for both unmarried and married individuals remains an open question. To address this concern, we controlled for marital status in the primary analyses and conducted supplemental analyses to see if results differed for married and unmarried participants.

\section{Gender and Couple Considerations}

There are several reasons to consider whether religiosity may differentially influence men and women. Consistent research shows differences between men and women in the domains of religiosity (e.g., Ahrold \& Meston, 2010; Luquis, Brelsford, \& Rojas-Guyler, 2012) and sexuality (e.g., Leonhardt \& Willoughby, 2019; Petersen \& Hyde, 2010). Women tend to be more religious 
than men (e.g., Ahrold \& Meston, 2010; Luquis et al., 2012); men tend to be more permissive in their sexual attitudes than women (Petersen \& Hyde, 2010). Additionally, literature and art from Christian theology (a theology belonging to a high percentage of our participants) have depicted women like Eve as an archetypal Femme Fatale, or a "temptress" without giving the same attention to male sexuality (Farley, 1976; Nicolson, 1993). Perhaps harsher religious judgments about women's sexuality could result in a greater likelihood of inhibited women's sexual expression.

These gendered considerations could also play a role in the couple context. Considering (a) the consistent links between religiosity, sexual sanctification, and sexual satisfaction for women and men (e.g., Hernandez et al., 2011; Leonhardt et al., 2020), (b) interdependence theory suggesting how partners' reports can influence actors (e.g., Rusbult \& Van Lange, 2008), and (c) the value of shared religious beliefs (Kusner, Mahoney, Pargament, \& DeMaris, 2014), it one partner's report of religiosity, sexual sanctification, and/or inhibited sexual passion may influence the other. For example, one study (Kusner et al., 2014) found that a husband's marital sanctification predicted lower negativity for himself, higher positivity for himself, and higher positivity in his wife; a wife's marital sanctification only predicted higher positivity in herself and marginally predicted higher positivity in her husband's. This highlights the value of considering differences between men and women in a couple context.

\section{Current Studies}

Previous research suggested an indirect link between religiosity and sexual satisfaction through sexual sanctification (Leonhardt et al., 2020), but we have more to learn about the negative mechanisms behind religiosity's sometimes negative association with sexual satisfaction (Davidson et al., 2004). In Study 1, we sought to replicate the positive indirect association between religiosity and sexual satisfaction through sexual sanctification. We also tested inhibited sexual passion as a mechanism that may account for the potentially negative association between religiosity and sexual satisfaction. Furthermore, in Study 2, we explored how these associations play out in a sample of mixed-sex couples. Using an Actor-Partner Interdependence Model (Ledermann, Macho, \& Kenny, 2011), we were able to test partner effects as well as whether actor effects hold when accounting for both partners' perspectives.

\section{Study 1}

For Study 1, we hypothesized that religiosity would have a positive indirect association with sexual satisfaction through sexual sanctification and a negative indirect association with sexual satisfaction through inhibited sexual passion. We also assessed similarities between women and men.

\section{Sample and Procedure}

The sample consisted of 1,695 sexually active individuals (640 men, 1,059 women) from Amazon's Mechanical Turk (MTurk; http://www.mturk.com), who had been in a committed, romantic relationship for at least two years and were residents of the United States. The sample is distinct from the sample used by Leonhardt et al., 2020 on a similar topic. MTurk is a website dedicated to online labor and is used to employ "workers" from around the world to complete specific tasks. The MTurk sample originally had 1,790 individuals. We removed the 95 who missed more than one out of five attention check questions (e.g., If you are reading this closely, please select "Strongly Agree"). We did not find any issues with bots or duplicate data when checking for patterns in IP addresses and GPS coordinates (Bai, 2018). We also scanned data of participants who took less than five minutes, but we did not detect any problems with their data. Our sample size ensured that we would have enough participants to assess small associations in complex structural equation models. Kline (2016) recommends at least 10 cases for every observed variable, well within the parameters of our study.

The study was approved by the institutional review board (IRB) at Brigham Young University. Regarding the current project, a job was posted inviting participants to complete a short survey on sexuality in a relationship. Participants were instructed that they needed to be English speaking and in a committed relationship for at least two years. Those who were interested were directed to a separate website (Qualtrics) to complete an online assessment. Before beginning the online survey, participants were asked to indicate informed consent and were informed about their rights as a research participant. Upon completion of the survey, participants were thanked for their time and given compensation of $\$ 0.50$. Consistent with typical MTurk samples, we note that the sample used was less religious than typical U.S. samples. Full demographic descriptive statistics are listed in Table 1.

\section{Measures}

Religiosity. Four items from the RELATE study (Busby, Holman, \& Taniguchi, 2001) assessed global religiosity: "Spirituality is an important part of my life" ( $1=$ never; 5 = very often $)$, "How often do you pray (commune with a higher power)?" $(1=$ never; $5=$ very often), "How important is your religious faith to you" $(1=$ not important; 5 = very important $)$, "How often do you attend religious services?" ( $1=$ never; $5=$ weekly). The Cronbach's alpha was .93 for men and .92 for women.

Inhibited sexual passion. Inhibited sexual passion was measured with a subscale from the Triadic Model of Sexual Passion (Busby, Leonhardt, \& James, 2019; Busby, Chiu, et al., 2019). Several data sets have provided psychometric validation of the scale (see Busby, Chiu, et al., 2019; Busby, Leonhardt, et al., 2019) and highlighted its divergent and convergent validity with variables such as sexual desire and sexual satisfaction. Four items were used for the scale (i.e. "I often feel reluctant to act on sexual urges that I have for my partner," "I am hesitant to participate in various sexual opportunities presented to me in my relationship with my partner," "Sometimes I have so many worries that I feel constrained from doing sexual activities I enjoy with my partner," "Generally, I feel inhibited in doing sexual acts with my partner that I am interested in") on a 5-point scale ( $1=$ never; $5=$ weekly). The Cronbach's alpha was .84 for men and .84 for women.

Sexual sanctification. An adaptation of Hernandez et al. (2011) sanctification of sexuality measure, specifically the Sacred Qualities subscale, was utilized to assess sexual sanctification in the relationship (e.g., "The sexual bond I have with my 
Table 1

Descriptive Statistics for Demographic Variables

\begin{tabular}{|c|c|c|c|c|c|c|}
\hline \multirow[b]{2}{*}{ Variables } & \multicolumn{3}{|c|}{ Study 1 (N = 1695 individuals $)$} & \multicolumn{3}{|c|}{ Study $2(\mathrm{~N}=481$ dyads/962 individuals $)$} \\
\hline & $M$ or $\%$ & $S D$ & Range & $M$ or $\%$ & $S D$ & Range \\
\hline Age & 34.96 & 10.40 & $18-73$ & 39.92 & 12.14 & $18-82$ \\
\hline Relationship length & 95.01 & 88.02 & $24-590$ & 134.69 & 120.50 & $24-720$ \\
\hline \multicolumn{7}{|l|}{ Gender } \\
\hline Men & $37.5 \%$ & & & - & - & - \\
\hline Women & $62.4 \%$ & & & - & - & - \\
\hline \multicolumn{7}{|l|}{ Sexual orientation } \\
\hline Completely homosexual & $9.4 \%$ & & & $7.3 \%$ & & \\
\hline Mostly homosexual & $2.3 \%$ & & & $1.0 \%$ & & \\
\hline Bisexual & $8.5 \%$ & & & $5.6 \%$ & & \\
\hline Mostly heterosexual & $11.4 \%$ & & & $5.8 \%$ & & \\
\hline Completely heterosexual & $68.4 \%$ & & & $80.3 \%$ & & \\
\hline \multicolumn{7}{|l|}{ Race } \\
\hline White & $77.9 \%$ & & & $74.1 \%$ & & \\
\hline Asian & $4.7 \%$ & & & $3.1 \%$ & & \\
\hline African & $6.5 \%$ & & & $10.4 \%$ & & \\
\hline Latino & $6.2 \%$ & & & $8.5 \%$ & & \\
\hline Mixed/biracial & $3.6 \%$ & & & $2.5 \%$ & & \\
\hline Native American & $0.6 \%$ & & & $0.7 \%$ & & \\
\hline Other & $0.6 \%$ & & & $1.3 \%$ & & \\
\hline \multicolumn{7}{|l|}{ Relationship status } \\
\hline Married & $51.7 \%$ & & & $66.9 \%$ & & \\
\hline Cohabiting & $29.7 \%$ & & & $30.4 \%$ & & \\
\hline Dating, never married & $14.3 \%$ & & & $1.5 \%$ & & \\
\hline Other & $4.3 \%$ & & & $1.2 \%$ & & \\
\hline \multicolumn{7}{|l|}{ Education } \\
\hline High school or less & $9.4 \%$ & & & $28.7 \%$ & & \\
\hline Some college & $40.7 \%$ & & & $39.5 \%$ & & \\
\hline 4-year degree & $34.2 \%$ & & & $22.2 \%$ & & \\
\hline Advanced & $15.7 \%$ & & & $9.6 \%$ & & \\
\hline \multicolumn{7}{|l|}{ Income } \\
\hline None & $4.3 \%$ & & & $7.9 \%$ & & \\
\hline Under $\$ 20,000$ & $16.4 \%$ & & & $14.2 \%$ & & \\
\hline$\$ 20,000-39,999$ & $27.0 \%$ & & & $25.7 \%$ & & \\
\hline$\$ 40,000-59,999$ & $24.0 \%$ & & & $20.7 \%$ & & \\
\hline$\$ 60,000-79,999$ & $14.0 \%$ & & & $11.9 \%$ & & \\
\hline$\$ 80,000+$ & $14.3 \%$ & & & $19.6 \%$ & & \\
\hline \multicolumn{7}{|l|}{ Religious affiliation } \\
\hline Christian & $50.1 \%$ & & & $55.7 \%$ & & \\
\hline Atheist & $11.5 \%$ & & & $4.1 \%$ & & \\
\hline Agnostic & $12.2 \%$ & & & $7.7 \%$ & & \\
\hline No affiliation & $16.5 \%$ & & & $24.0 \%$ & & \\
\hline Other & $9.7 \%$ & & & $8.5 \%$ & & \\
\hline
\end{tabular}

partner is sacred to me"). The adaptation was using language inclusive of committed relationships broadly rather than referring explicitly to marriage and shortening the scale to five items. Responses ranged on a 7-point Likert scale ( $1=$ strongly disagree; 7 = strongly agree). The Cronbach's alpha was .93 for men and women.

Sexual satisfaction. The Global Measure of Sexual Satisfaction (GMSEX; Lawrance \& Byers, 1995) was created to assess overall sexual satisfaction. The GMSEX has a root question of "In general, how would you describe your sexual relationship with your partner?" The participants then responded to five separate items, each on a 7-point scale, reporting their overall sexual satisfaction: (a) Good-Bad, (b) Pleasant-Unpleasant, (c) PositiveNegative, (d) Satisfying-Unsatisfying, and (e) ValuableWorthless. The Cronbach's alpha was .95 for men and .97 for women.
Control variables. Age and relationship length were each assessed with open ended questions. Race and marital status were dichotomized so that all participants were coded as either White (1) or non-White (0), and (0) unmarried or (1) married. Sexual orientation was assessed on a 5-point scale $(1=$ Completely Homosexual; 5 = Completely Heterosexual). Education was assessed on a 7-point scale $(1=$ Less than High School; $7=$ Doctorate [PhD, J.D., M.D., etc.]), and income was assessed on a 12-point scale $(1=$ none; $12=\$ 300,000$ or above $)$.

\section{Data Analysis Plan}

We conducted $t$ tests by gender (see Table 2), bivariate correlations (see Table 3), and measurement invariance tests (Table S1). Afterward, we estimated a series of SEM models, each increasing in complexity. For the $t$ tests by gender and bivariate correlations, 
Table 2

Descriptive Statistics and Gender Differences of Control, Predictor, and Dependent Variables

\begin{tabular}{|c|c|c|c|c|c|c|c|c|c|c|c|c|}
\hline \multirow[b]{3}{*}{ Variable } & \multicolumn{6}{|c|}{ Study 1} & \multicolumn{6}{|c|}{ Study 2} \\
\hline & \multirow{2}{*}{$\begin{array}{l}\text { Response } \\
\text { range }\end{array}$} & \multicolumn{2}{|c|}{ Men } & \multicolumn{2}{|c|}{ Women } & \multirow[b]{2}{*}{$t$ value } & \multirow{2}{*}{$\begin{array}{l}\text { Response } \\
\text { range }\end{array}$} & \multicolumn{2}{|c|}{ Men } & \multicolumn{2}{|c|}{ Women } & \multirow[b]{2}{*}{$t$ value } \\
\hline & & $M$ & $S D$ & $M$ & $S D$ & & & M & $S D$ & $M$ & $S D$ & \\
\hline Age & $18-73$ & 35.61 & 10.68 & 34.57 & 10.21 & $2.00^{*}$ & $18-82$ & 41.08 & 12.30 & 38.70 & 11.90 & $9.99^{* * * *}$ \\
\hline White & $0-1$ & .75 & .43 & .75 & .43 & -.12 & $0-1$ & .73 & .45 & .76 & .43 & 1.78 \\
\hline Education & $1-7$ & 4.34 & 1.35 & 4.16 & 1.28 & $2.84^{* * *}$ & $1-7$ & 3.49 & 1.48 & 3.68 & 1.41 & $3.12^{* *}$ \\
\hline Income & $1-12$ & 4.28 & 1.84 & 3.59 & 1.63 & $8.03^{* * * *}$ & $1-12$ & 4.31 & 2.08 & 3.70 & 2.04 & $6.99^{* * * *}$ \\
\hline Relationship length (months) & $24-590$ & 94.84 & 92.77 & 95.11 & 85.09 & -.06 & 24-720 & - & - & 134.69 & 120.50 & - \\
\hline Heterosexual & $1-5$ & 4.34 & 1.35 & 4.23 & 1.23 & 1.72 & $1-5$ & 4.59 & 1.11 & 4.42 & 1.16 & $4.86^{* * * *}$ \\
\hline Married & $0-1$ & .52 & .50 & .52 & .50 & -.04 & $0-1$ & - & - & .67 & .47 & - \\
\hline Religiosity & $1-5$ & 2.58 & 1.31 & 2.87 & 1.29 & $4.35^{* * * *}$ & $1-5$ & 2.86 & 1.28 & 3.12 & 1.19 & $6.01^{* * * *}$ \\
\hline Inhibited sexual passion & $1-5$ & 2.51 & 1.02 & 2.32 & 1.03 & $3.58^{* * * *}$ & $1-5$ & 2.31 & .97 & 2.48 & .97 & $3.96^{* * * *}$ \\
\hline Sexual sanctification & $1-7$ & 3.84 & 1.76 & 3.71 & 1.84 & 1.37 & $1-7$ & 4.13 & 1.76 & 4.16 & 1.78 & .56 \\
\hline Sexual satisfaction & $1-7$ & 5.65 & 1.37 & 5.56 & 1.67 & 1.13 & $1-7$ & 6.05 & 1.18 & 5.91 & 1.28 & $2.90^{* * *}$ \\
\hline
\end{tabular}

Note. Women's report of relationship length and relationship were used for the couple dataset.

${ }^{*} p<.05 .^{* * *} p<.01 .^{* * * *} p<.001$.

the items for constructs were averaged together to create a mean score for scales of interest. For both the measurement models and subsequent SEM models, all individual items of scales were modeled as latent variables for their corresponding constructs.

We first estimated measurement models to increase confidence in the validity of the latent variables (Kline, 2016). We then created SEM models for women and men to estimate the direct effect of religiosity on sexual satisfaction with all controls inserted (age, race, education, income, relationship length, sexual orientation, and marital status). Finally, we inserted sexual sanctification and inhibited sexual passion as variables between religiosity and sexual satisfaction and conducted 5,000 bootstraps to obtain results for indirect effects (see Figure 1). $T$ tests and correlations were conducted in Stata 15.1 (StataCorp, 2017), measurement invariance was conducted in AMOS 23.0 (Arbuckle, 2014), and final SEM analyses were conducted in MPlus 7.11 (Muthén \& Muthén, 1998-2012). As an additional robustness test, we conducted supplemental analyses by testing all final models for married and unmarried individuals with and without control variables (Table S2, Figure S1, Figure S2). Output from all main analyses and supplemental analyses are available on the OSF website (https:// osf.io/8u2jq/).

\section{Results}

Preliminary analyses. Gender differences were explored for all variables of interest and controls. Table 2 shows response ranges, means, standard deviations, and $t$ values for each variable. We then assessed the bivariate associations between the variables of interest for both men and women (see Table 3). We also conducted measurement invariance tests. Religiosity and sexual sanctification failed to reach weak invariance; inhibited sexual passion and sexual satisfaction failed to reach strong invariance (Table S1). The failure to reach measurement invariance suggests direct comparisons should not be made between women and men, so we estimated different models for each.

Structural equation models.

Measurement models. Both final measurement models fit the data adequately $\left(\right.$ men: $\chi^{2}(129)=354.56, \mathrm{CFI}=.98, p<.001$, RMSEA $=.05$, SRMR $=.03$; women: $\chi^{2}(129)=750.39, p<$

Table 3

Bivariate Correlations Between Control, Predictor, and Outcome Variables (Study 1)

\begin{tabular}{|c|c|c|c|c|c|c|c|c|c|c|c|}
\hline Variable & 1 & 2 & 3 & 4 & 5 & 6 & 7 & 8 & 9 & 10 & 11 \\
\hline 1. Age & - & $.10^{* * *}$ & .00 & $.15^{* * * *}$ & $.52^{* * * * *}$ & $.09^{* *}$ & $.23^{* * * *}$ & $.20^{* * * *}$ & $-.09^{* * *}$ & -.02 & $-.09^{* *}$ \\
\hline 2. White & $.09^{*}$ & - & -.01 & -.02 & $.13^{* * * *}$ & .03 & - & $-.10^{* * *}$ & -.05 & -.09 & .04 \\
\hline 3. Education & $.15^{* * * *}$ & -.02 & - & $.29^{* * * * *}$ & $-.07^{*}$ & .03 & .03 & .01 & .02 & -.05 & .01 \\
\hline 4. Income & $.25^{* * * *}$ & .07 & $.37^{* * * *}$ & - & $.07^{*}$ & .01 & $.17^{* * * *}$ & $.10^{* * *}$ & .06 & .05 & -.01 \\
\hline 5. Relationship length & $.63^{* * * *}$ & $.12^{* * *}$ & $.16^{* * * *}$ & $.20^{* * * *}$ & - & $.07^{*}$ & $.49^{* * * *}$ & $.14^{* * * *}$ & -.01 & -.05 & $-.09^{* *}$ \\
\hline 6. Heterosexual & .04 & -.07 & .02 & .03 & .04 & - & $.08^{* * *}$ & $.14^{* * * *}$ & -.02 & .03 & .00 \\
\hline 7. Married & $.27^{* * * *}$ & - & $.17^{* * * * *}$ & $.27^{* * * * *}$ & $.46^{* * * * *}$ & .03 & - & $.17^{\text {***** }}$ & .01 & -.02 & $-.09^{* *}$ \\
\hline 8. Religiosity & $.15^{* * * *}$ & $-.10^{*}$ & $.13^{* *}$ & .07 & $.09^{*}$ & $.12 * *$ & $.16^{* * * *}$ &. & .02 & $.40^{* * * * *}$ & .02 \\
\hline 9. Inhibited sexual passion & $-.14^{* * * *}$ & $-.09^{*}$ & -.02 & -.06 & $-.08^{*}$ & .01 & .03 & $.12^{* * *}$ & - & $-.07^{*}$ & $-.31^{\text {***** }}$ \\
\hline 10. Sexual sanctification & .04 & $-.19^{* * * *}$ & .03 & .07 & .01 & $.11^{* * *}$ & .05 & $.49^{* * * * *}$ & $-.11^{* * *}$ & - & $.44^{* * * * *}$ \\
\hline 11. Sexual satisfaction & -.06 & $-.11^{* * *}$ & .02 & -.03 & $-.12^{\text {*** }}$ & .04 & -.07 & -.00 & $-.23^{* * * *}$ & $.29^{* * * * *}$ & - \\
\hline
\end{tabular}

Note. Men's correlations are below the diagonal. Women's correlations are above the diagonal. Correlations between two dichotomous variables are precluded.

${ }^{*} p<.05 .^{* *} p<.01 .^{* * * *} p<.001$. 


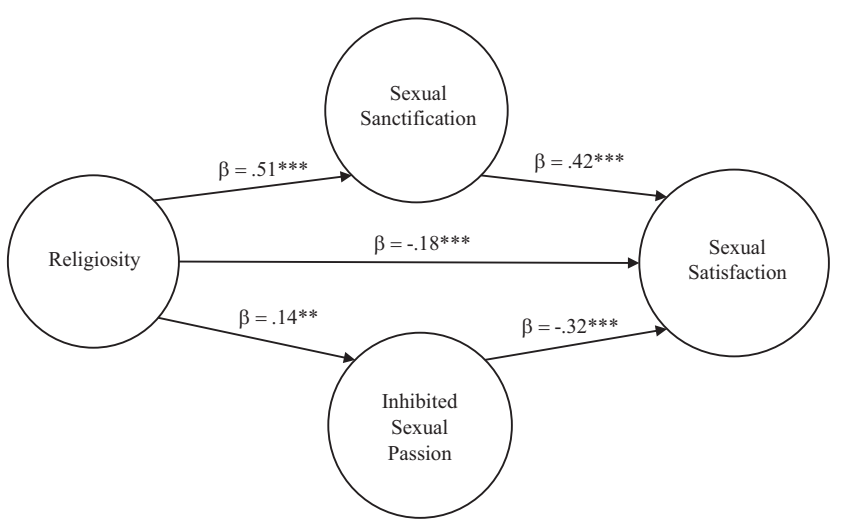

Figure 1. Study 1 structural equation model for men's religiosity predicting sexual sanctification, inhibited sexual passion, and sexual satisfaction. Analyses controlled for age, relationship length, race, sexual orientation, and marital status. Model fit: $\chi^{2}(234)=568.83, p<.001$, CFI $=$ .97, RMSEA $=.04$, SRMR $=.05 .{ }^{* *} p<.01 .^{* * * *} p<.001$.

$.001, \mathrm{CFI}=.97$, RMSEA $=.07$, SRMR $=.04)$. All factor loadings were above .71 for men and above .72 for women.

Nonindirect effects structural equation models. The models had good fit $\left(\right.$ men: $\chi^{2}(82)=226.29, p<.001$ CFI $=.97$, RMSEA $=.05$, SRMR $=.06$; women: $\chi^{2}(82)=351.09, p<.001$, $\mathrm{CFI}=.98$, RMSEA $=.06$, SRMR $=.06)$. Religiosity was not associated with sexual satisfaction for men $(\beta=-.01, p=.88)$ or women $(\beta=.05, p=.12)$.

Indirect effects model for men. The model had adequate fit, $\chi^{2}(234)=568.83, p<.001 \mathrm{CFI}=.97, \mathrm{RMSEA}=.05, \mathrm{SRMR}=$ .05 . Figure 1 shows all direct effects for variables of interest. Table 4 shows all indirect effects. Broadly, religiosity had a positive indirect association with sexual satisfaction through sexual sanctification, a negative indirect association with sexual satisfaction through inhibited sexual passion, and a negative direct association with sexual satisfaction.

Indirect effects model for women. The model had adequate fit, $\chi^{2}(234)=1048.40, p<.001 \mathrm{CFI}=.95$, RMSEA $=.06$, $\mathrm{SRMR}=.05$. Figure 2 shows all direct effects of interest and Table 4 shows all indirect effects. Similar to the model for men, religiosity had an indirect positive association with sexual satisfaction through sexual sanctification and a negative direct association with sexual satisfaction. Religiosity had no indirect association with sexual satisfaction through inhibited sexual passion.

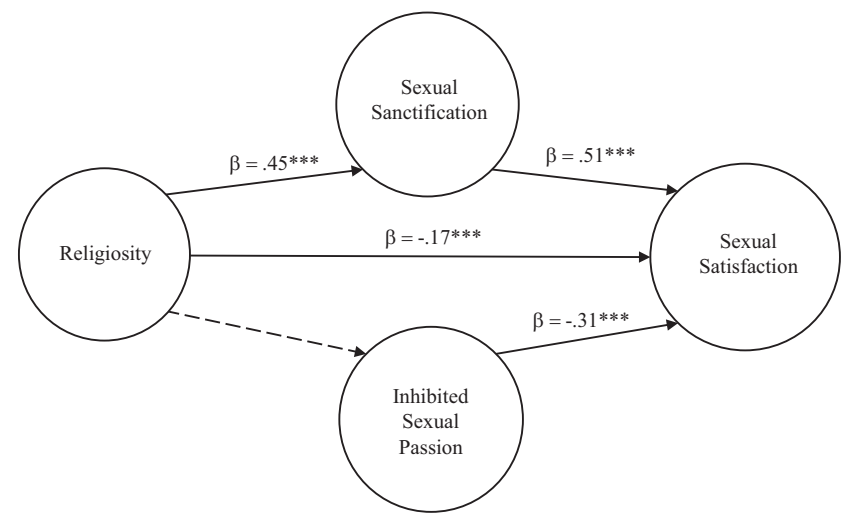

Figure 2. Study 1 structural equation model for women's religiosity predicting sexual sanctification, inhibited sexual passion, and sexual satisfaction. Dashed pathway from religiosity to inhibited sexual passion indicates nonsignificance. Analyses controlled for age, relationship length, race, sexual orientation, and marital status. Model fit: $\chi^{2}(234)=1048.40$, $p<.001, \mathrm{CFI}=.95, \mathrm{RMSEA}=.06, \mathrm{SRMR}=.05 .{ }^{* * * *} p<.001$.

Supplemental analysis. Results were almost completely consistent between married participants and unmarried participants for both men (Figure S1, Table S2) and women (Figure S2, Table S2). The one notable exception is that religiosity had an indirect effect on sexual satisfaction through inhibited sexual passion for unmarried men $(\beta=-.06$, CI 95\% $[-.32,-.05])$ but not married men $(\beta=-.03$, CI 95\% $[-.09, .01])$.

\section{Study 2}

Study 2 was preregistered and our specific hypotheses are available on the OSF website (https://osf.io/8u2jq/). Based off the results from Study 1, we expected that the indirect association from religiosity to sexual satisfaction through sexual sanctification would hold for the actor effects. We had less confidence predicting what may happen with partner effects, but we were broadly interested in exploring whether there was any consistency with inhibited sexual passion as a mechanism, as well as what partner effects might exist. Considering minor differences between women and men in Study 1, we also continued to ask whether any differences existed between women and men in this study.

Table 4

Total, Indirect, and Direct Effects of Religiosity Predicting Sexual Satisfaction Through Inhibited Sexual Passion and Sexual Sanctification (Study 1)

\begin{tabular}{|c|c|c|c|c|c|c|}
\hline \multirow[b]{2}{*}{ Indirect effects } & \multicolumn{3}{|c|}{ Men sexual satisfaction } & \multicolumn{3}{|c|}{ Women sexual satisfaction } \\
\hline & $\beta$ & $S E$ & $\mathrm{CI}$ & $\beta$ & $S E$ & CI \\
\hline Religiosity $\rightarrow$ Sexual satisfaction (direct effect) & -.18 & .05 & {$[-.25,-.10]$} & -.17 & .03 & {$[-.22,-.17]$} \\
\hline Religiosity $\rightarrow$ Sexual sanctification $\rightarrow$ sexual satisfaction & .21 & .03 & {$[.17, .26]$} & .23 & .02 & {$[.20, .26]$} \\
\hline Religiosity $\rightarrow$ Inhibited sexual passion $\rightarrow$ sexual satisfaction & -.05 & .02 & {$[-.07,-.02]$} & -.01 & .01 & {$[-.03, .01]$} \\
\hline Religiosity $\rightarrow$ Sexual satisfaction (total indirect) & .17 & .04 & {$[.12,22]$} & .22 & .03 & {$[.18, .26]$} \\
\hline Religiosity $\rightarrow$ Sexual satisfaction (total effect) & -.01 & .05 & {$[-.08, .07]$} & .05 & .03 & {$[-.00, .11]$} \\
\hline
\end{tabular}




\section{Sample and Procedure}

After approval from the IRB at Brigham Young University, the data were collected with the company Bovitz Inc. (http://bovitzinc .com/). We originally targeted a sample of 500 couples. Similar to Study 1, this sample size allowed us to estimate complicated SEM models and detect a small effect size (Kline, 2016). To participate, couples were required to speak English, be in a committed relationship for at least two years, and complete at least $80 \%$ of the survey. From Bovitz Inc. panel of couples, 975 individuals attempted to sign up for the survey and recruit their partners to complete the survey as well. Of the original individuals, $406 \mathrm{had}$ unusable couple data due to at least one member of the dyad not consenting, failing to answer the question on gender (making it impossible to organize the data), or the second partner dropping out of the survey shortly after consenting. An additional 54 observations were dropped because participants either failed an attention check question or completed less than $80 \%$ of the survey. An additional 34 indistinguishable dyads were dropped, leaving 481 distinguishable dyads for the final SEM analyses. All data were cleaned based upon these criteria before conducting primary analyses for the study. Participants were instructed that they needed to be English speaking, and those who were interested were directed to a separate website (Qualtrics) to complete an online assessment. Before beginning the online survey, participants were asked to indicate informed consent and were informed about their rights as a research participant. When both members of the dyad completed the survey, participants were thanked for their time and given compensation of $\$ 8.00$ per dyad and a Bovitz loyalty credit valued at $67 \phi$. Consistent with our first sample, the participants for our second study were less religious than typical U.S. samples (26\% unaffiliated; Pew Research Center, 2019). Only 33.1\% of the couples were unmarried. Full demographics are shown in Table 1.

\section{Measures}

Religiosity. The scale from Study 1 was the same used in Study 2. The Cronbach's alpha was acceptable for both men (.92) and women (.90).

Inhibited sexual passion. The scale from Study 1 was the same used in Study 2. The Cronbach's alpha was acceptable for both men (.81) and women (.83).
Sexual sanctification. The scale from Study 1 was the same used in Study 2. The Cronbach's alpha was acceptable for both men (.93) and women (.93.)

Sexual satisfaction. The scale from Study 1 was the same used in Study 2. The Cronbach's alpha was acceptable for both men (.92) and women (.90).

Control variables. Age, relationship length, race, marital status, sexual orientation, education, and income were assessed the same as in Study 1.

\section{Data Analysis Plan}

We largely followed the same data analysis plan as Study 1 . We conducted paired $t$ tests to assess differences between men and women and bivariate correlations. The SEM models also had a similar analysis plan, but this time included both partners' perspectives in an APIM mediation model (Ledermann et al., 2011). $T$ tests and correlations were conducted in Stata 15.1 (StataCorp, 2017), and all SEM analyses were conducted in MPlus 7.11 (Muthén \& Muthén, 1998-2012). As an additional robustness test, we conducted supplemental analyses separate for married and unmarried couples, both with and without control variables. Though there was a slight modification, as we had insufficient statistical power to analyze all variables as latent (Kline, 2016). As such manifest variables were used rather than latent variables for the supplemental analyses. Results were highly consistent, with a couple of exceptions highlighted below (full results in Table S3 and Figure S3). Output from main analyses and supplemental analyses are available on the OSF website (https://osf.io/8u2jq/).

\section{Results}

Preliminary analyses. Gender differences were explored for all variables of interest and controls. Table 2 shows response ranges, means, standard deviations, and $t$ values for each variable. We then assessed the bivariate associations between the variables of interest for both women and men (see Table 5 for full results). We also conducted measurement invariance tests. We reached strong invariance between women and men for sexual sanctifica-

Table 5

Bivariate Correlations Between Control Variables, Predictor Variables, and Outcome Variables (Study 2)

\begin{tabular}{|c|c|c|c|c|c|c|c|c|c|c|c|}
\hline Variable & 1 & 2 & 3 & 4 & 5 & 6 & 7 & 8 & 9 & 10 & 11 \\
\hline 1. Age & $.91^{\text {***** }}$ & $.10^{*}$ & -.09 & .03 & $.60^{* * * *}$ & $.15^{* * * * *}$ & $.22^{* * * *}$ & $.20^{* * *}$ & $-.11^{*}$ & -.00 & $-.17^{* * * *}$ \\
\hline 2. White & $.11^{*}$ & $.62^{* * * *}$ & .02 & .02 & $.14^{* *}$ & .01 & - & -.07 & .01 & .00 & .04 \\
\hline 3. Education & .01 & .04 & $.59^{* * *}$ & $.42^{\text {***** }}$ & -.05 & .06 & $.19^{* * * *}$ & $.10^{*}$ & .03 & .09 & .02 \\
\hline 4. Income & .08 & .05 & $.54^{* * * *}$ & $.57^{* * * *}$ & -.00 & .02 & $.18^{* * * *}$ & .09 & .01 & $.12^{* * *}$ & .07 \\
\hline 5. Relationship length & $.56^{* * * *}$ & $.17^{* * * *}$ & -.02 & .05 & - & $.13^{* *}$ & $.33^{* * * *}$ & .09 & -.02 & -.09 & $-.16^{* * * *}$ \\
\hline 6. Heterosexual & .07 & .03 & -.00 & .02 & $.10^{*}$ & $.78^{* * * *}$ & .06 & .07 & -.03 & .03 & .04 \\
\hline 7. Married & $.22^{* * * *}$ & - & $.19^{* * * *}$ & $.19^{* * * *}$ & $.33^{* * *}$ & .03 & - & $.22^{* * * *}$ & -.02 & .09 & -.01 \\
\hline 8. Religiosity & $.14^{* *}$ & $-.16^{* * * *}$ & $.17^{* * * * *}$ & .03 & .03 & -.09 & $.12^{* *}$ & $.72^{* * * * *}$ & $-.10^{*}$ & $.46^{* * * * *}$ & .03 \\
\hline 9. Inhibited sexual passion & $-.09^{*}$ & $.10^{*}$ & .04 & -.03 & -.05 & -.06 & -.02 & .03 & $.54^{* * * *}$ & -.04 & $-.30^{* * * *}$ \\
\hline 10. Sexual sanctification & .04 & $-.12^{*}$ & .08 & .07 & $-.09^{*}$ & -.03 & .06 & $.56^{\text {******* }}$ & .04 & $.72^{* * * * *}$ & $.41^{* * * * *}$ \\
\hline 11. Sexual satisfaction & $-.10^{*}$ & -.02 & .00 & .06 & $-.15^{* * *}$ & .07 & -.01 & .05 & $-.32^{* * * *}$ & $.31^{* * * * *}$ & $.64^{* * * *}$ \\
\hline
\end{tabular}

Note. Men's correlations are below the diagonal. Women's correlations are above the diagonal. Bolded correlations are the correlations between the partners. Correlations between two dichotomous variables are precluded.

${ }^{*} p<.05 .{ }^{* * *} p<.01{ }^{* * * *} p<.001$. 
tion, but failed to reach strong invariance for religiosity, inhibited sexual passion, and sexual satisfaction (Table S1).

\section{Structural equation models.}

Measurement model. The measurement model fit the data adequately, $\chi^{2}(548)=1079.63, p<.001, \mathrm{CFI}=.96, \mathrm{RMSEA}=$ $.05, \mathrm{SRMR}=.04$. All factor loadings were above .54 for men and above .64 for women.

Nonindirect effects structural equation model. The model had good fit, $\chi^{2}(280)=575.42, p<.001$, CFI $=.96$, RMSEA $=$ .05, SRMR $=.06$. Religiosity of both partners was unrelated to sexual satisfaction for either partner (men to men: $\beta=.04, p=$ .62 ; women to women: $\beta=-.02, p=.83$; men to women: $\beta=$ $.11, p=.11$; women to men: $\beta=.04, p=.56$ ).

Indirect effects model. The model had adequate fit, $\chi^{2}(848)=$ $1503.86, p<.001 \mathrm{CFI}=.96$, RMSEA $=.04, \mathrm{SRMR}=.05$. Figure 3 shows all direct effects of interest; Table 6 shows all indirect effects. Holistically, both men's and women's own religiosity was indirectly, positively associated with sexual satisfaction through sexual sanctification. There were no indirect associations through inhibited sexual passion. There was also a negative direct association between one's own religiosity and one's own sexual satisfaction after taking all variables into account. Furthermore, there was an indirect partner association on sexual satisfaction, as men's religiosity positively predicted women's sexual sanctification.

Supplemental analysis. Results were highly consistent between married couples and unmarried couples (Figure S3, Table
S3), but there were some small differences. Women's religiosity had a direct negative association with sexual satisfaction for unmarried $(\beta=-.35$, CI 95\% $[-.60,-.09])$, but not married participants $(\beta=-.05$, CI 95\% [-.20, .09]). Also, for married couples, men's religiosity predicted high women's sexual satisfaction through her sanctification $(\beta=.20, \mathrm{CI} 95 \%[.10, .29])$, but not for unmarried couples $(\beta=.08$, CI 95\% $[-.02, .18])$.

\section{Discussion}

In studies highlighting the complexity of how religiosity might indirectly influence sexual satisfaction, the most consistent takeaway is that religiosity has the potential to positively influence sexual satisfaction through sexual sanctification. This finding seems robust considering this has been found in a previous study (Leonhardt et al., 2020), replicated in our individual dataset and also found in our couple dataset. This also is consistent with the growing body of research showing that sexual sanctification is associated with positive sexual outcomes for newlyweds (Hernandez et al., 2011; Hernandez-Kane \& Mahoney, 2018), unmarried adults (Murray-Swank et al., 2005) and same-sex unions (Phillips et al., 2017). Altogether, people report benefits from sexual sanctification, irrespective of whether they are engaging in traditionally theologically sanctioned unions (married and mixed-sex) versus traditionally unsanctioned unions (unmarried and same-sex).

The what, when, and how dissonating traditional theological prohibition and reported psychological benefit could be a profit-

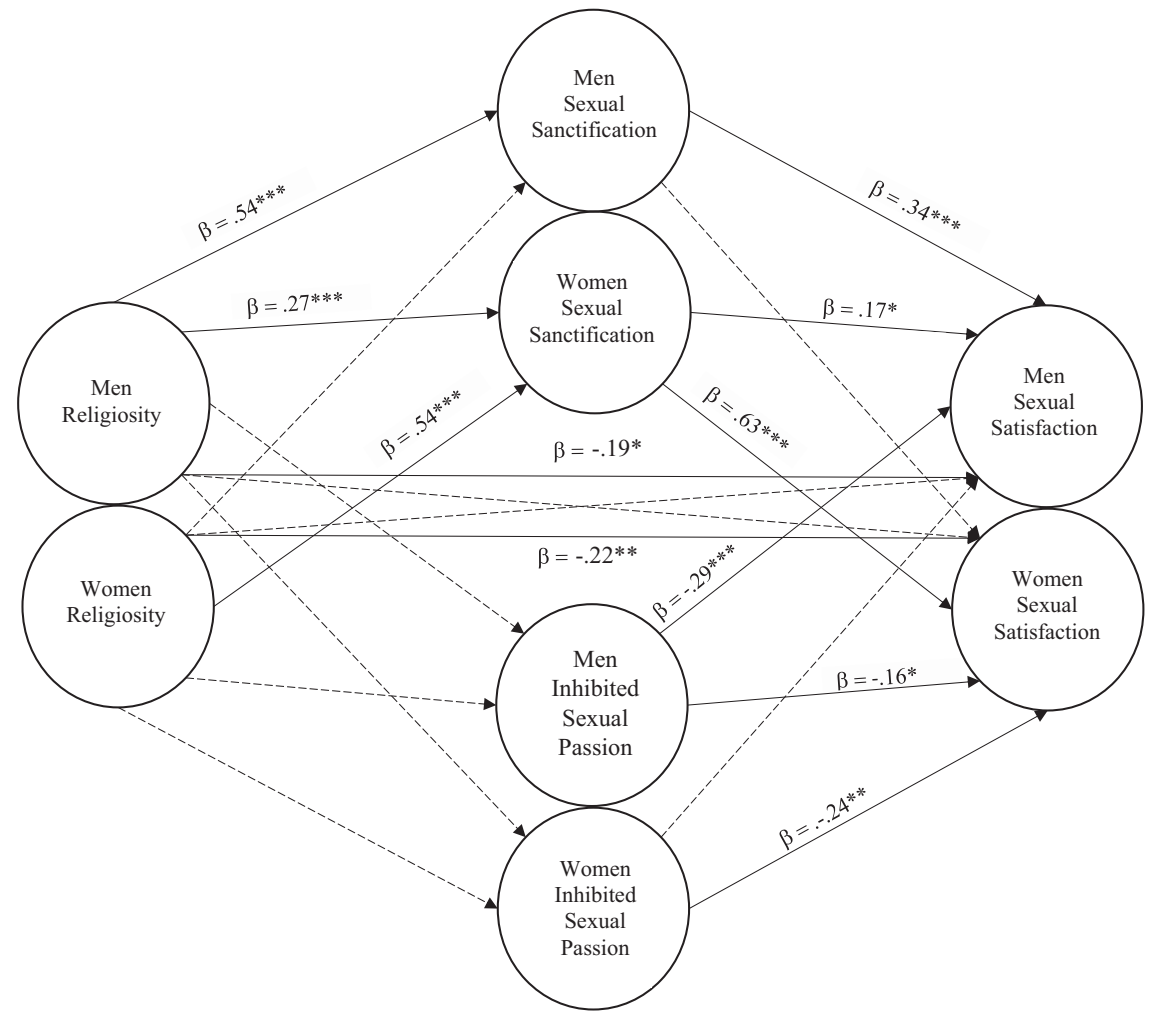

Figure 3. Study 2 actor-partner interdependence structural equation model for religiosity predicting sexual sanctification, inhibited sexual passion, and sexual satisfaction. Dashed pathways indicates nonsignificance. Analyses controlled for age, relationship length, race, sexual orientation, and marital status. Model fit: $\chi^{2}(848)=$ 1503.86, $p<.001$, CFI $=.96$, RMSEA $=.04$, SRMR $=.05 .{ }^{*} p<.05 .{ }^{* * *} p<.01 .^{* * * *} p<.001$. 
Table 6

Total, Indirect, and Direct Effects of Religiosity Predicting Sexual Satisfaction Through Inhibited Sexual Passion and Sexual Sanctification (Study 2)

\begin{tabular}{|c|c|c|c|c|c|c|c|}
\hline \multirow[b]{2}{*}{ Indirect effects } & \multicolumn{3}{|c|}{ Men sexual satisfaction } & \multicolumn{3}{|c|}{ Women sexual satisfaction } & \multirow[b]{2}{*}{ CI } \\
\hline & $\beta$ & $S E$ & $\mathrm{CI}$ & Indirect effects & $\beta$ & $S E$ & \\
\hline WRel $\rightarrow$ MSat (direct effect) & -.05 & .07 & {$[-.16, .07]$} & WRel $\rightarrow$ WSat (direct effect) & -.22 & .08 & {$[-.35,-.09]$} \\
\hline WRel $\rightarrow$ WSan $\rightarrow$ MSat & .05 & .03 & {$[.01, .10]$} & WRel $\rightarrow$ WSan $\rightarrow$ WSat & .19 & .05 & {$[.10, .28]$} \\
\hline WRel $\rightarrow$ MSan $\rightarrow$ MSat & .03 & .02 & {$[-.01, .07]$} & WRel $\rightarrow$ MSan $\rightarrow$ WSat & -.01 & .01 & {$[-.03, .01]$} \\
\hline WRel $\rightarrow$ WInh $\rightarrow$ MSat & .02 & .02 & {$[-.01, .04]$} & WRel $\rightarrow$ WInh $\rightarrow$ WSat & .03 & .02 & {$[-.01, .06]$} \\
\hline WRel $\rightarrow$ MInh $\rightarrow$ MSat & -.01 & .02 & {$[-.04, .03]$} & WRel $\rightarrow$ MInh $\rightarrow$ WSat & -.00 & .01 & {$[-.03, .02]$} \\
\hline WRel $\rightarrow$ MSat (total indirect) & .09 & .05 & {$[.01, .17]$} & WRel $\rightarrow$ WSat (total indirect) & .21 & .05 & {$[.12,29]$} \\
\hline WRel $\rightarrow$ MSat (total effect) & .04 & .07 & {$[-.07, .15]$} & WRel $\rightarrow$ WSat (total effect) & -.02 & .10 & {$[-.17,14]$} \\
\hline MRel $\rightarrow$ MSat (direct effect) & -.19 & .08 & {$[-.31,-.06]$} & MRel $\rightarrow$ WSat (direct effect) & .01 & .08 & {$[-.11, .14]$} \\
\hline MRel $\rightarrow$ WSan $\rightarrow$ MSat & .05 & .02 & {$[.01, .08]$} & MRel $\rightarrow$ WSan $\rightarrow$ WSat & .17 & .05 & {$[.10, .25]$} \\
\hline MRel $\rightarrow$ MSan $\rightarrow$ MSat & .18 & .05 & {$[.10, .26]$} & MRel $\rightarrow$ MSan $\rightarrow$ WSat & -.07 & .05 & {$[-.15, .01]$} \\
\hline MRel $\rightarrow$ WInh $\rightarrow$ MSat & -.01 & .01 & {$[-.03, .02]$} & MRel $\rightarrow$ WInh $\rightarrow$ WSat & -.01 & .02 & {$[-.04, .02]$} \\
\hline MRel $\rightarrow$ MInh $\rightarrow$ MSat & .00 & .02 & {$[-.03, .04]$} & MRel $\rightarrow$ MInh $\rightarrow$ WSat & .00 & .01 & {$[-.02, .02]$} \\
\hline MRel $\rightarrow$ MSat (total indirect) & .22 & .05 & {$[.14,31]$} & MRel $\rightarrow$ WSat (total indirect) & .10 & .06 & {$[.00, .19]$} \\
\hline MRel $\rightarrow$ MSat (total effect) & .04 & .07 & {$[-.08, .15]$} & MRel $\rightarrow$ WSat (total effect) & .11 & .09 & {$[-.04, .26]$} \\
\hline
\end{tabular}

Note. $\quad$ MRel $=$ men religiosity; MSat $=$ men sexual satisfaction; MSan $=$ men sexual sanctification; MInh $=$ men inhibited sexual passion; WRel $=$ women religiosity; WSat $=$ women sexual satisfaction; WSan $=$ women sexual sanctification; WInh $=$ women inhibited sexual passion.

able endeavor for future research, especially considering the overwhelming majority of unmarried adult Americans are not reserving sex for marriage (likely above 90\%; Finer, 2007; Regnerus \& Uecker, 2011). Even most unmarried adults who attend religious services several times a month engage in nonmarital sex (Wilcox \& Wolfinger, 2016). Perhaps dangers of premarital sex are not as heavily emphasized in contemporary religion (Hernandez et al., 2014). Perhaps beliefs about marriage result in marriage being a less sharp transition for sexual beliefs and practices than past generations (Willoughby \& James, 2017). Between intertangled theological understanding and beliefs about sexuality and/or marriage, yet to be identified subpopulations of religious individuals may only experience the psychological benefits of sexual sanctification in marriage. But up to this point, evidence suggests that people experience psychological benefits from sexual sanctification across a variety of contexts.

Though the indirect association from religiosity to sexual satisfaction through sexual sanctification was robust in this study, other associations were less clear and may be more contingent upon contexts we were not able to adequately address. Inhibited sexual passion was not an effective mechanism for religiosity predicting lower sexual satisfaction in our studies. The only evidence of an indirect association through inhibited sexual passion was for unmarried men in Study 1. This suggests the possibility of religiosity being a contributing factor to inhibiting sexual passion expression. This finding, however, is blunted by Study 2 showing that men's religiosity was unrelated to inhibited sexual passion in the SEM models. Overall, inhibited sexual passion was not an effective mechanism predicting a negative indirect association from religiosity to sexual satisfaction, even though sexual inhibition had a significant negative association with sexual satisfaction.

We did, however, find additional evidence that the study of religious dualities in the sexual domain deserves further attention. When accounting for all the variables in our SEM models, sanctification was a specific, proximal religious belief that indirectly explained the positive association between religiosity and sexual satisfaction, but a previously nonsignificant direct association between religiosity and sexual satisfaction became a direct negative association. This was found in both studies for both women and men. We need more research, and perhaps a more in-depth understanding of couple context, to better understand potential negative mechanisms. It would be valuable to assess how religiosity influences sexual attitudes at an earlier stage of the relationship, as Hackathorn et al., 2016 found that religiosity was linked with sexual guilt for unmarried individuals (but not married). The mean relationship length of their participants, however, was two and a half years for unmarried participants; our studies had mean relationship lengths of eight years and 11 years for Study 1 and Study 2 , respectively. Perhaps our unmarried participants had been in a committed relationship long enough that they no longer experienced inhibitions or sexual guilt such as in the Hackathorn et al., 2016 study. Additionally, Hackathorn et al., 2016 used a more comprehensive measure of sexual guilt that could be useful to test in future research.

Results across gender were similar across studies, though there were some differences in cross-gender partner effects. Men's inhibited sexual passion predicted lower sexual satisfaction for women, and men's religiosity predicting women's sexual sanctification, and thus indirectly predicting her sexual satisfaction through her sanctification (but only for married couples). The partner effect for inhibited sexual passion is relatively straightforward. Previous research has suggested that men are expected to be the more sexually assertive partner in the relationship. By violating this expectation, men's inhibited sexuality could be more problematic in the relationship than women's inhibited sexuality (KatzWise \& Hyde, 2014). The partner effect from men's religiosity for married couples invites the question of why men's religiosity is a moderate predictor of women's sanctification (for married couples), but not vice versa. This is a matter that requires further inquiry, but we offer some speculation that may guide further investigation. This may have something to do with the principle of least interest (e.g., Sprecher, Schmeeckle, \& Felmlee, 2006). For 
example, women are traditionally considered something of a gatekeeper to sexual interaction, as the average woman reports less sexual interest than the average man (Buss \& Schmitt, 2019), and men are expected to be the more sexually assertive partner (KatzWise \& Hyde, 2014). On the other hand, men report lower religiosity than women. Just as women are sometimes considered gatekeepers to sexuality in general, it may be possible that men are sometimes gatekeepers to the spiritual dimension of sexuality, as perhaps there is higher expectation for women to bring a spiritual dimension to the sexual relationship. Again, our explanation and understanding of this is speculative and requires additional study.

\section{Limitations and Future Directions}

Our study had several strengths, such as advancing a theory on religious dualities (Dollahite et al., 2018; Mahoney, 2010; Mahoney et al., 2001), multiple large samples (including dyadic data), exploring gender differences, and advanced methodology for complex hypotheses. The study also had limitations. One limitation is cross-sectional data: We cannot claim causality or directionality. Though we believe that the direction of our analyses makes the most theoretical sense. Ample theory and empirical study suggest that religiosity can influence attitudes and behavior surrounding sexuality (e.g., Hernandez et al., 2014), which in turn can influence sexual satisfaction (e.g., Hackathorn et al., 2016; Hardy \& Willoughby, 2017; Hernandez et al., 2011; Leonhardt et al., 2020). With cross-sectional data, it is important to remain open to inverse associations. It seems, however, less likely that satisfying sex would lead to viewing the sexual relationship as sanctified, which in turn leads to becoming more religious.

Although our measures were psychometrically sound, they still had limitations. For example, we used a global religiosity measure, sacrificing some of the complexity that can be found in its multifaceted nature of religious beliefs, practices, and communities (e.g., Dollahite, Marks, \& Goodman, 2004; Hardy \& Willoughby, 2017). We also were limited by our measure of sexual sanctification, as other research has highlighted the value of both theistic and nontheistic sanctification (e.g., Hernandez et al., 2011). Many individuals in the United States report belief in God or a universal spirit, making theistic sanctification a potentially important consideration for future research. In fact, sanctification research often includes the theistic subscale even when participants identify as agnostic or atheist (e.g., Hernandez et al., 2011). The inhibited sexual passion scale is a new measure, and it would be valuable to see how closely it relates to a more comprehensive measures of sexual guilt. It also would be valuable to more fully explore how these variables relate to a wide variety of sexual quality outcomes, as sexual satisfaction can be an unclear general outcome for what the sexual relationship actually looks like (Leonhardt, Spencer, Butler, \& Theobald, 2019; Pascoal, Narciso, \& Pereira, 2014). Additionally, these results should be considered across specific religious affiliations. Some affiliations may be more likely to instill positive teachings about sexuality, while others are more likely to instill negative teachings. Perhaps latent class analyses would be a profitable future direction to try and parcel out subgroups that differentially experience religiosity's influence on sexuality.

\section{Conclusion}

The connection between religiosity and sexuality is complicated. The indirect association between religiosity and higher sexual satisfaction through sexual sanctification seems robust, but we need to deepen our understanding on how religiosity might have an indirect negative influence on sexual satisfaction. We hope this study opens a wide variety of avenues to explore constructs and contextual factors behind how religion influences a sexual relationship. With additional study, perhaps this young body of work can help people maximize potential benefits of their belief systems in their sexual relationships.

\section{References}

Ahrold, T. K., \& Meston, C. M. (2010). Ethnic differences in sexual attitudes of U.S. college students: Gender, acculturation, and religiosity factors. Archives of Sexual Behavior, 39, 190-202. http://dx.doi.org/10 .1007/s10508-008-9406-1

Arbuckle, J. L. (2014). Amos (version 23.0) [Computer Program]. Chicago, IL: IBM SPSS.

Ashdown, B. K., Hackathorn, J., \& Clark, E. M. (2011). In and out of the bedroom: Sexual satisfaction in the marital relationship. Journal of Integrated Social Sciences, 2, 40-57.

Augustine. (1998). The confessions (M. Boulder, Trans.). New York, NY: Vintage Books. (Original work published 400).

Bai, H. (2018). Evidence that a large amount of low quality responses on MTurk can be detected with repeated GPS coordinates. Retrieved from https://www.maxhuibai.com/blog/evidence-that-responses-fromrepeating-gps-are-random

Bogaert, A. F. (2004). Asexuality: Prevalence and associated factors in a national probability sample. Journal of Sex Research, 41, 279-287. http://dx.doi.org/10.1080/00224490409552235

Busby, D. M., Chiu, H. Y., Leonhardt, N. D., \& Iliff, E. (2019). Sexual passion in committed relationships: Measurement and conceptual issues. Family Process, 58, 734-748. http://dx.doi.org/10.1111/famp.12385

Busby, D. M., Holman, T. B., \& Taniguchi, N. (2001). RELATE: Relationship evaluation of the individual, family, cultural, and couple contexts. Family Relations, 50, 308-316. http://dx.doi.org/10.1111/j.17413729.2001.00308.x

Busby, D. M., Leonhardt, N. D., \& James, S. (2019). A closer look at sexual passion in relationships. Journal of Child and Family Studies. Advance online publications. http://dx.doi.org/10.1007/s10826-01901682-4

Buss, D. M. (2002). Sex, marriage, and religion: What adaptive problems do religious phenomena solve? Psychological Inquiry, 13, 201-203. http://dx.doi.org/10.1207/S15327965PLI1303_05

Buss, D. M., \& Schmitt, D. P. (2019). Mate preferences and their behavioral manifestations. Annual Review of Psychology, 70, 77-110. http:// dx.doi.org/10.1146/annurev-psych-010418-103408

Coplan, R. J., Prakash, K., O’Neil, K., \& Armer, M. (2004). Do you "want" to play? Distinguishing between conflicted shyness and social disinterest in early childhood. Developmental Psychology, 40, 244-258. http://dx .doi.org/10.1037/0012-1649.40.2.244

Cowden, C. R., \& Bradshaw, S. D. (2007). Religiosity and sexual concerns. International Journal of Sexual Health, 19, 15-24. http://dx.doi.org/10 .1300/J514v19n01_03

Davidson, J. K., Moore, N. B., \& Ullstrup, K. M. (2004). Religiosity and sexual responsibility: Relationships of choice. American Journal of Health Behavior, 28, 335-346. http://dx.doi.org/10.5993/AJHB.28.4.5

Dollahite, D. C., Marks, L. D., \& Dalton, H. (2018). How religion helps and harms families: A conceptual model of a system of dualities at the nexus of faith and family life. Journal of Family Theory \& Review, 10, 219-241. http://dx.doi.org/10.1111/jftr.12242 
Dollahite, D. C., Marks, L. D., \& Goodman, M. (2004). Families and religious beliefs, practices, and communities: Linkages in a diverse and dynamic cultural context. In M. J. Coleman \& L. H. Ganong (Eds.), The handbook of contemporary families: Considering the past contemplating the future (pp. 411-431). Thousand Oaks, CA: Sage. http://dx.doi.org/ 10.4135/9781412976022.n24

Emmers-Sommer, T. M., Allen, M., Schoenbauer, K. V., \& Burrell, N. (2018). Implications of sex guilt: A meta-analysis. Marriage \& Family Review, 54, 417-437. http://dx.doi.org/10.1080/01494929.2017 .1359815

Farley, M. A. (1976). Sources of sexual inequality in the history of Christian thought. The Journal of Religion, 56, 162-176. http://dx.doi .org/10.1086/486481

Finer, L. B. (2007). Trends in premarital sex in the United States, 19542003. Public Health Reports, 122, 73-78. http://dx.doi.org/10.1177/ 003335490712200110

Freud, S. (1961). The future of an illusion. New York, NY: Norton. (Original work published 1927)

Hackathorn, J. M., Ashdown, B. K., \& Rife, S. C. (2016). The sacred bed: Sex guilt mediates religiosity and satisfaction for unmarried people. Sexuality \& Culture, 20, 153-172. http://dx.doi.org/10.1007/s12119015-9315-0

Hardy, S. A., \& Willoughby, B. J. (2017). Religiosity and chastity among single young adults and married adults. Psychology of Religion and Spirituality, 9, 285-295. http://dx.doi.org/10.1037/rel0000112

Hernandez, K. M., Mahoney, A., \& Pargament, K. I. (2011). Sanctification of sexuality: Implications for newlyweds' marital and sexual quality. Journal of Family Psychology, 25, 775-780. http://dx.doi.org/10.1037/ a0025103

Hernandez, K. M., Mahoney, A., \& Pargament, K. I. (2014). Sexuality and religion. In D. L. Tolman \& L. M. Diamond (Eds.), APA handbook of psychology and sexuality: Vol. 2: Contextual Approaches (pp. 425447). Washington, DC: American Psychological Association. http://dx .doi.org/10.1037/14194-013

Hernandez-Kane, K. M., \& Mahoney, A. (2018). Sex through a sacred lens: Longitudinal effects of sanctification of marital sexuality. Journal of Family Psychology, 32, 425-434. http://dx.doi.org/10.1037/ fam0000392

Katz-Wise, S. L., \& Hyde, J. S. (2014). Sexuality and gender: The interplay. In D. Tolman, L. Diamond, J. Bauermeister, W. George, J. Pfaus, \& L. Ward (Eds.), APA handbook of sexuality and psychology, Vol. 1: Person-based approaches (pp. 31-62). http://dx.doi.org/10.1037/14193002

Kline, R. B. (2016). Principles and practice of structural equation modeling. New York, NY: Guilford Press.

Kusner, K. G., Mahoney, A., Pargament, K. I., \& DeMaris, A. (2014). Sanctification of marriage and spiritual intimacy predicting observed marital interactions across the transition to parenthood. Journal of Family Psychology, 28, 604-614. http://dx.doi.org/10.1037/a0036989

Lawrance, K., \& Byers, E. S. (1995). Sexual satisfaction in long-term heterosexual relationships: The interpersonal exchange model of sexual satisfaction. Personal Relationships, 2, 267-285. http://dx.doi.org/10 .1111/j.1475-6811.1995.tb00092.x

Ledermann, T., Macho, S., \& Kenny, D. A. (2011). Assessing mediation in dyadic data using the actor-partner interdependence model. Structural Equation Modeling, 18, 595-612. http://dx.doi.org/10.1080/10705511 .2011 .607099

Leonhardt, N. D., Busby, D. M., \& Willoughby, B. J. (2020). Sex guilt or sanctification? The indirect role of religiosity on sexual satisfaction. Psychology of Religion and Spirituality, 12, 213-222. http://dx.doi.org/ 10.1037/rel0000245

Leonhardt, N. D., Spencer, T. J., Butler, M. H., \& Theobald, A. C. (2019). Sexual media and sexual quality: Aims, distinctions, and reflexivity-
Response to commentaries. Archives of Sexual Behavior, 48, 22912303. http://dx.doi.org/10.1007/s10508-019-01551-7

Leonhardt, N. D., \& Willoughby, B. J. (2019). Pornography, provocative sexual media, and their differing associations with multiple aspects of sexual satisfaction. Journal of Social and Personal Relationships, 36, 618-641. http://dx.doi.org/10.1177/0265407517739162

Luquis, R. R., Brelsford, G. M., \& Rojas-Guyler, L. (2012). Religiosity, spirituality, sexual attitudes, and sexual behaviors among college students. Journal of Religion and Health, 51, 601-614. http://dx.doi.org/ 10.1007/s10943-011-9527-z

Mahoney, A. (2010). Religion in families 1999 to 2009: A relational spirituality framework. Journal of Marriage and Family, 72, 805-827. http://dx.doi.org/10.1111/j.1741-3737.2010.00732.x

Mahoney, A., Pargament, K. I., Jewell, T., Swank, A. B., Scott, E., Emery, E., \& Rye, M. (1999). Marriage and the spiritual realm: The role of proximal and distal religious constructs in marital functioning. Journal of Family Psychology, 13, 321-338. http://dx.doi.org/10.1037/08933200.13.3.321

Mahoney, A., Pargament, K. I., Tarakeshwar, N., \& Swank, A. B. (2001). Religion in the home in the 1980s and 1990s: A meta-analytic review and conceptual analysis of links between religion, marriage, and parenting. Journal of Family Psychology, 15, 559-596. http://dx.doi.org/10 .1037/0893-3200.15.4.559

Murray, K. M., Ciarrocchi, J. W., \& Murray-Swank, N. A. (2007). Spirituality, religiosity, shame and guilt as predictors of sexual attitudes and experiences. Journal of Psychology and Theology, 35, 222-234. http:// dx.doi.org/10.1177/009164710703500305

Murray-Swank, N. A., Pargament, K. I., \& Mahoney, A. (2005). At the crossroads of sexuality and spirituality: The sanctification of sex by college students. International Journal for the Psychology of Religion, 15, 199-219. http://dx.doi.org/10.1207/s15327582ijpr1503_2

Muthén, L. K., \& Muthén, B. O. (1998-2012). MPlus user's guide (7th ed.). Los Angeles, CA: Author.

Nicolson, P. (1993). Deconstructing sexology: Understanding the pathologization of female sexuality. Journal of Reproductive and Infant Psychology, 11, 191-201. http://dx.doi.org/10.1080/02646839308403218

Pargament, K. I., Oman, D., Pomerleau, J., \& Mahoney, A. (2017). Some contributions of a psychological approach to the study of the sacred. Religion, 47, 718-744. http://dx.doi.org/10.1080/0048721X.2017 .1333205

Pascoal, P. M., Narciso, I. S., \& Pereira, N. M. (2014). What is sexual satisfaction? Thematic analysis of lay people's definitions. Journal of Sex Research, 51, 22-30. http://dx.doi.org/10.1080/00224499.2013 .815149

Petersen, J. L., \& Hyde, J. S. (2010). A meta-analytic review of research on gender differences in sexuality, 1993-2007. Psychological Bulletin, 136, 21-38. http://dx.doi.org/10.1037/a0017504

Peterson, J. A. (1964). Education for marriage (2nd ed.). New York, NY: Scribner.

Pew Research Center. (2019). In U.S. decline of Christianity continues at rapid pace. Retrieved from https://www.pewforum.org/2019/10/17/inu-s-decline-of-christianity-continues-at-rapid-pace/

Phillips III, R. E., Avant, S., Kalp, D., Cenkner, D., Lucci, M., Herndon, R., \& Maccarelli, A. (2017). Initial validation of measures of sanctification in same-sex romantic relationships and sexual behavior. Journal for the Scientific Study of Religion, 56, 836-851. http://dx.doi.org/10 $.1111 /$ jssr. 12488

Regnerus, M., \& Uecker, J. (2011). Premarital sex in America: How young Americans meet, mate, and think about marrying. New York, NY: Oxford University Press.

Rosenbaum, J. E., \& Weathersbee, B. (2013). True love waits: Do Southern Baptists? Premarital sexual behavior among newly married Southern Baptist Sunday school students. Journal of Religion and Health, 52, 263-275. http://dx.doi.org/10.1007/s10943-010-9445-5 
Runkel, G. (1998). Sexual morality of Christianity. Journal of Sex \& Marital Therapy, 24, 103-122. http://dx.doi.org/10.1080/0092623 9808404924

Rusbult, C. E., \& Van Lange, P. A. (2008). Why we need interdependence theory. Social and Personality Psychology Compass, 2, 2049-2070. http://dx.doi.org/10.1111/j.1751-9004.2008.00147.x

Schnarch, D. M. (1991). Constructing the sexual crucible: An integration of sexual and marital therapy. New York, NY: W. W. Norton Company.

Sprecher, S., Schmeeckle, M., \& Felmlee, D. (2006). The principle of least interest: Inequality in emotional involvement in romantic relationships. Journal of Family Issues, 27, 1255-1280. http://dx.doi.org/10.1177/ $0192513 X 06289215$

StataCorp. (2017). Stata statistical software: Release 15. College Station, TX: StataCorp LLC.
Wilcox, W. B., \& Wolfinger, N. (2016). Soul mates: Religion, sex, love, and marriage among African Americans and Latinos. New York City, NY: Oxford University Press. http://dx.doi.org/10.1093/acprof:oso/ 9780195394221.001.0001

Willoughby, B. J., \& James, S. L. (2017). The marriage paradox: Why emerging adults love marriage yet push it aside. New York, NY: Oxford University Press. http://dx.doi.org/10.1093/acprof:oso/9780190296650 .001 .0001

Received November 18, 2019 Revision received July 13, 2020 Accepted July 20, 2020 